\title{
CONCISE
}

PUBLICATIONS

\section{Evidence for Stimulation of Renal Gluconeogenesis by Catecholamines}

\author{
Kiyoshi Kurokawa and Shaul G. Massry \\ From the Renal and Hypertension Service, the Department of Medicine, and \\ the Medical Research Institute, Cedars-Sinai Medical Center, and the \\ Department of Medicine, University of California Los Angeles School of \\ Medicine, Los Angeles, California 90048
}

A в S T R A C T Isoproterenol and norepinephrine $\left(10^{-4}\right.$ M) significantly increased cyclic AMP formation and glucose production by the isolated tubules of the renal cortex of the rat. These effects were abolished by propranolol. Theophylline diminished the effects of the catecholamines on gluconeogenesis despite a marked augmentation in cyclic AMP concentration. In the absence of calcium ion in the incubation medium, isoproterenol stimulates cyclic AMP production, but has no effect on gluconeogenesis. It is concluded that catecholamines enhance gluconeogenesis in renal cortical tubules by the stimulation of beta adrenergic receptors. This effect is probably mediated through adenyl cyclase-cyclic AMP system and requires an adequate level of ATP and the presence of calcium ion.

\section{INTRODUCTION}

It has been shown that the renal cortex can produce glucose from a variety of substrates (1). This process of renal gluconeogenesis is influenced by the concentrations of hydrogen and calcium ions in the incubation media as well as by parathyroid hormone (PTH) and cyclic AMP (1-7). Since both PTH and catecholamines stimulate the adenyl cyclase activity of homogenates

Dr. Massry is an Established Investigator of the American Heart Association.

Received for publication 23 October 1972 and in revised form 16 January 1973. from renal cortex of the rat $(8,9)$ and increase the cyclic AMP concentration in renal cortical slices of the $\operatorname{dog}(10)$, it is possible that catecholamines also influence renal gluconeogenesis. The present investigation was undertaken to evaluate the effects of catecholamines on renal gluconeogenesis utilizing the isolated renal cortical tubules of the rat.

\section{METHODS}

Wistar male rats, weighing 180-200 g, were used. The preparation of isolated tubules from the renal cortex, the experimental procedures, and the analytical methods for the determinations of glucose and adenosine triphosphate (ATP) levels were done according to the methods described by Nagata and Rasmussen (5, 6). In short, renal cortical tubules, containing 5-6 mg proteins, were incubated at $37^{\circ} \mathrm{C}$ for $20 \mathrm{~min}$ in $1.2 \mathrm{ml}$ of Krebs-Ringer bicarbonate buffer, $\mathrm{pH} \mathrm{7.4,} \mathrm{containing} 2 \%$ bovine serum albumin, $0.5 \mathrm{mM}$ palmitate, and $5 \mathrm{mM}$ alpha-ketoglutarate with a mixture of $95 \% \mathrm{O}_{2}$ and $5 \% \mathrm{CO}_{2}$ as a gas phase. The concentration of $\mathrm{CaCl}_{2}$ in the buffer was $1.0 \mathrm{mM}$ and that of bicarbonate, $25 \mathrm{mM}$. The incubations were carried out in the presence or absence of $\mathrm{PTH}$, catecholamines, propranolol, cyclic AMP, or theophylline. Some studies with isoproterenol were carried out utilizing a calcium-free buffer but with $0.1 \mathrm{mM}$ ethyleneglycol-bis ( $\beta$-aminoethylether) $N, N^{\prime}$-tetraacetic acid (EGTA). After the incubation, perchloric acid extracts were prepared. These extracts were neutralized with $3 \mathrm{M} \mathrm{K}_{2} \mathrm{CO}_{3}$ in $0.5 \mathrm{M}$ triethanolamine to $\mathrm{pH}$ 5.5-6.5

${ }^{1}$ Abbreviations used in this paper: AMP, adenosine $3^{\prime}, 5^{\prime}-$ monophosphate; ATP, adenosine triphosphate; EGTA, ethyleneglycol-bis ( $\beta$-aminoethylether) $N, N^{\prime}$-tetraacetic acid; $\mathrm{PTH}$, parathyroid hormone. 
and then analyzed for glucose and ATP by fluorometry (5, $6)$.

For the measurements of cyclic AMP concentrations, cortical tubules were incubated in the same way except for the omissions of palmitate and alpha-ketoglutarate from the incubation medium. First, the incubations were carried out for $10 \mathrm{~min}$ with and without $10 \mathrm{mM}$ theophylline. Then, $\mathrm{PTH}$, catecholamines, or propranolol were added in a total volume of $10 \mu \mathrm{l}$, and the incubations were continued for one additional minute at $37^{\circ} \mathrm{C} ; 0.9 \mathrm{ml}$ of $10 \%$ trichloroacetic acid was added to the media which was then centrifuged for $10 \mathrm{~min}$ at $1000 \mathrm{~g}$. Trichloroacetic acid was extracted three times from the supernate with 5 vol of water-saturated ether. The remaining ether was removed by placing the supernate in a boiling water bath for $3 \mathrm{~min}$. Cyclic AMP concentration was measured by the method of Gilman (11).

\section{RESULTS AND DISCUSSION}

The effects of PTH, catecholamines, cyclic AMP, and propranolol on glucose production and cyclic AMP concentration in the isolated tubules of the renal cortex of the rat are presented in Table I. The variations in the control rate of glucose production observed in the various experiments (Table I) are probably due to the different tubular preparations used. Our results on the effects of PTH and cyclic AMP are similar to previ- ously reported data (5-7) and are presented here for comparison with the effects of the catecholamines. Both isoproterenol and norepinephrine produced a significant $(P<0.01)$ increase in glucose production from alpha-ketoglutarate by the renal cortical tubules. Since the catecholamines also augmented cyclic AMP formation and since cyclic AMP increased glucose production as well, it is likely that the effect of catecholamines on glucose formation is mediated by cyclic AMP. Propranolol, a beta adrenergic blocking agent, abolished the stimulatory effects of isoproterenol and norepinephrine on both gluconeogenesis and cyclic AMP concentration. These observations indicate that the effects of the catecholamines on gluconeogenesis are produced by the stimulation of beta adrenergic receptors in renal cortex. Since the additions of propranolol alone to the incubation medium significantly suppressed gluconeogenesis, it could be argued that this drug may inhibit the gluconeogenic activity of the renal cortical cells. However, an increase in hydrogen ion concentration in the incubation medium $\left(\mathrm{HCO}_{3}{ }^{-}=10 \mathrm{mM}, \mathrm{pH} 7.0\right)$ in the presence of propranolol resulted in a significant augmentation of gluconeogenesis from $26.7 \pm 0.8$ to

TABLE I

Effects of Catecholamines, Parathyroid Hormone, Cyclic AMP, and Theophylline on Glucose Production from Alpha-ketoglutarate and on Cyclic AMP Concentrations in the Isolated Tubules from Renal Cortex of Rat

\begin{tabular}{lcc}
\hline & Glucose production & Cyclic AMP \\
\hline & nmol/mg protein/20 min & pmol/mg protein \\
Control & $24.2 \pm 0.8$ & $12.8 \pm 0.4$ \\
Isoproterenol, $10^{-4} \mathrm{M}$ & $30.8 \pm 1.0$ & $18.6 \pm 0.6$ \\
Norepinephrine, $10^{-4} \mathrm{M}$ & $31.3 \pm 0.7$ & $17.8 \pm 0.7$ \\
PTH, 5 $\mu \mathrm{g} / \mathrm{ml}$ & $31.8 \pm 0.6$ & $31.3 \pm 1.2$ \\
& & \\
Control & $26.7 \pm 0.4$ & - \\
Isoproterenol, $10^{-4} \mathrm{M}$ & $31.6 \pm 0.6$ & - \\
Cyclic AMP, $10^{-4} \mathrm{M}$ & $34.6 \pm 1.1$ & \\
& & \\
Control & $35.0 \pm 0.5$ & $13.4 \pm 1.3$ \\
Theophylline, $10 \mathrm{mM}$ & $10.1 \pm 0.2$ & $16.3 \pm 1.6$ \\
+ Isoproterenol, $10^{-4} \mathrm{M}$ & $11.7 \pm 0.4$ & $34.7 \pm 1.8$ \\
+ PTH, 5 $\mu \mathrm{g} / \mathrm{ml}^{-4} \mathrm{M}$ & $12.2 \pm 0.5$ & $122 \pm 8$ \\
+ Cyclic AMP, $10^{-4} \mathrm{M}$ & $10.6 \pm 0.3$ & - \\
Control & $38.0 \pm 1.5$ & $18.0 \pm 1.0^{*}$ \\
Isoproterenol, $10^{-4} \mathrm{M}$ & $42.1 \pm 0.7$ & $33.4 \pm 1.2^{*}$ \\
Propranolol, $10^{-3} \mathrm{M}$ & $26.7 \pm 0.8$ & $17.0 \pm 0.8^{*}$ \\
Propranolol & & \\
$\quad+$ Isoproterenol, $10^{-4} \mathrm{M}$ & $27.0 \pm 0.6$ & $17.3 \pm 1.1^{*}$ \\
$\quad+$ Norepinephrine, $10^{-4} \mathrm{M}$ & $26.5 \pm 0.8$ & $17.1 \pm 0.9^{*}$ \\
\hline
\end{tabular}

Values represent mean $\pm \mathrm{SE}$ of triplicate determinations.

* Theophylline, $10 \mathrm{mM}$, was added to the incubation media. 
$40.6 \pm 0.9 \mathrm{nmol} / \mathrm{mg}$ protein per $20 \mathrm{~min}$, suggesting that the cells were active and capable of glucose production.

The concentrations of catecholamines used are those which produced a maximal effect on both glucose formation and cyclic AMP concentrations. It is possible, however, that a further increment in the concentration of cyclic AMP may result in a greater production of glucose. Therefore, the effect of theophylline, an inhibitor of phosphodiesterase, was examined. Theophylline alone, in a concentration of $10 \mathrm{mM}$, produced a slight increment in the basal levels of cyclic AMP but augmented markedly the cyclic AMP concentrations in response to isoproterenol. However, glucose production was suppressed by theophylline both in the presence and absence of isoproterenol. Although the suppressive effect of theophylline on gluconeogenesis was noted by Pagliara and Goodman (12), the mechanisms for this inhibition are not known. In the present study, theophylline decreased the levels of ATP in the isolated tubules; ATP levels were $2.54 \pm 0.02$ and $3.37 \pm 0.07 \mathrm{nmol} / \mathrm{mg}$ protein with and without $10 \mathrm{mM}$ theophylline, respectively $(P<0.01)$. The gluconeogenic reaction catalyzed by phosphoglycerate kinase is coupled with ATP. Furthermore, the reaction catalyzed by a key gluconeogenic enzyme, phosphoenolpyruvate carboxykinase, is coupled with guanosine triphosphate, the level of which would vary in parallel with that of ATP. It seems, therefore, that the decrease in the level of ATP by theophylline may, at least in part, be responsible for the suppression of gluconeogenesis by this agent.

Since the actions of catecholamines on its target cells are thought to be accompanied by a change in calcium ion concentration in cell cytosol (13), and since gluconeogenesis is stimulated by calcium ion $(1,6)$, the effect of isoproterenol on glucose production by the renal cortex was evaluated in the absence and presence of calcium ion in the incubation medium. As depicted in Fig. 1, isoproterenol could not stimulate glucose production in the absence of calcium despite the stimulation of cyclic AMP production. The failure of isoproterenol to stimulate glucose production in the absence of calcium cannot be attributed to a lack of gluconeogenic capacity, since an increase in hydrogen ion concentration in the calcium-free medium is accompanied by enhanced gluconeogenesis $(5,7)$.

An increase in glucose production may not always represent gluconeogenesis, since breakdown of glycogen will also result in enhanced glucose formation. The kidney contains only minute amounts of glycogen, $0.01 \%$ of its wet weight, (14), and as such, is considered an excellent organ for the study of gluconeogenesis (1). It is, therefore, unlikely that the increase in glucose production observed in our study reflects glycogenolysis.

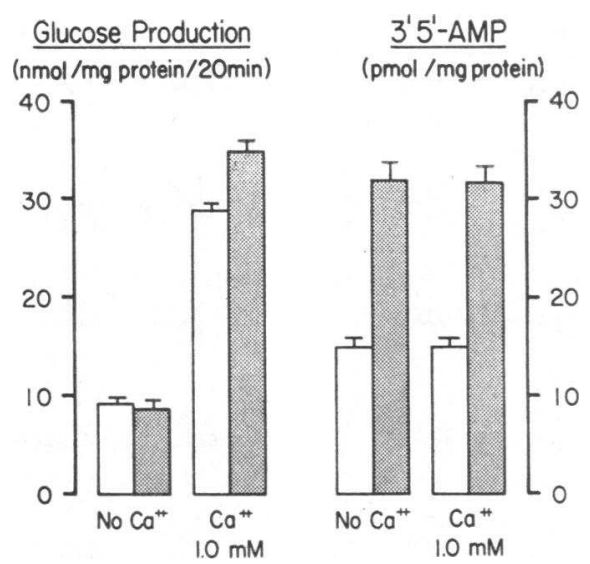

FIGURE 1 The effects of isoproterenol and calcium ion on glucose production and cyclic AMP formation in the isolated cortical tubules of the rat kidney. The shaded and open bars represent results from experiments with and without isoproterenol. Theophylline, $10 \mathrm{mM}$, was added to the incubation media in the experiments for cyclic AMP determinations. The data are represented as mean $\pm \mathrm{SE}$ of triplicate determinations.

Furthermore, catecholamines stimulate gluconeogenesis and cyclic AMP production in the liver as well (15).

The results of the present study demonstrate that catecholamines enhance gluconeogenesis in renal cortical tubules by the stimulation of beta adrenergic receptors. This gluconeogenic effect of the catecholamines is probably mediated through adenyl cyclase-cyclic AMP system and requires adequate levels of ATP and the presence of calcium ion.

\section{ACKNOWLEDGMENTS}

We are thankful for Miss Carolyn Mayson for her able technical assistance and for Mrs. Catherine Hoyt for secretarial help. Mr. Roger Heath did the art work.

This work was supported by General Research Support Grant RR05468 and Grant TAM05630 from the U. S. Public Health Service, and by a grant from the Kidney Foundation of Southern California.

\section{REFERENCES}

1. Krebs, H. A., D. A. H. Bennett, P. de Gasquet, T. Gascoyne, and T. Yoshida. 1963. Renal gluconeogenesis. The effects of diet on the gluconeogenic capacity of ratkidney-cortex slices. Biochem. J. 86: 22.

2. Goodman, A. D., R. E. Fuisz, and G. F. Cahill, Jr. 1966. Renal gluconeogenesis in acidosis, alkalosis, and potassium deficiency: its possible role in regulation of renal ammonia production. J. Clin. Invest. 45: 612.

3. Kamm, D. E., R. E. Fuisz, A. D. Goodman, and G. F. Cahill, Jr. 1967. Acid-base alterations and renal gluconeogenesis : effect of $\mathrm{pH}$, bicarbonate concentration, and

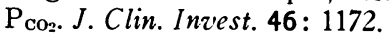

4. Pagliara, A. S., and A. D. Goodman. 1969. Effect of adenosine $3^{\prime}, 5^{\prime}$-monophosphate on production of glucose and ammonia by renal cortex. J. Clin. Invest. 48: 1408.

Catecholamines and Renal Gluconeogenesis 
5. Nagata, N., and H. Rasmussen. 1970. Parathyroid hormone, 3'5'-AMP, $\mathrm{Ca}^{++}$, and renal gluconeogenesis. Proc. Natl. Acad. Sci. U. S. A. 65: 368.

6. Nagata, N., and H. Rasmussen. 1970. Renal gluconeogenesis : effects of $\mathrm{Ca}^{++}$and $\mathrm{H}^{+}$. Biochim. Biophys. Acta. $215: 1$.

7. Rasmussen, H., and N. Nagata. 1970. Renal gluconeogenesis: effects of parathyroid hormone and dibutyryl 3',5'-AMP. Biochim. Biophys. Acta. 215: 17.

8. Chase, L. R., and G. D. Aurbach. 1968. Renal adenyl cyclase. Anatomically separate sites for parathyroid hormone and vasopressin. Science (Wash. D. C.). 159: 545.

9. Melson, G. L., L. R. Chase, and G. D. Aurbach. 1970. Parathyroid hormone-sensitive adenyl cyclase in isolated renal tubules. Endocrinology. 86: 511 .

10. Beck, N. P., S. W. Reed, H. V. Murdaugh, and B. B. Davis. 1972. Effects of catecholamines and their inter- action with other hormones on cyclic $3^{\prime}, 5^{\prime}$-adenosine monophosphate of the kidney. J. Clin. Invest. 51: 939.

11. Gilman, A. G. 1970. A protein binding assay for adenosine $3^{\prime}, 5^{\prime}$-cyclic monophosphate. Proc. Natl. Acad. Sci. U.S. A. $67: 305$.

12. Pagliara, A. S., and A. D. Goodman. 1970. Relation of renal cortical gluconeogenesis, glutamate content, and production of ammonia. J. Clin. Invest. 49: 1967.

13. Triggle, D. J. 1972. Adrenergic receptors. Ann. Rev' Pharmacol. 12: 185.

14. Marsh, J. B., and K. L. Miller. 1953. Demonstration of glycogen synthesis by rat kidney slices in vitro. Science (Wash. D. C.). 118: 416.

15. Exton, J. H., and C. R. Park. 1968. Control of gluconeogenesis in liver. II. Effects of glucagon, catecholamines, and adenosine $3^{\prime} 5^{\prime}$-monophosphate on gluconeogenesis in the perfused rat liver. J. Biol. Chem. 243: 4189. 